\title{
Rapid detection of Salmonella Typhi by loop-mediated isothermal amplification (LAMP) method
}

\author{
J. Abdullah ${ }^{1}$, N.Saffie ${ }^{1}$, F.A.R.Sjasri ${ }^{1}$, A.Husin ${ }^{3}$, Z.Abdul-Rahman ${ }^{2}$, A.Ismail ${ }^{1}$, \\ I. Aziah ${ }^{1}$, M. Mohamed ${ }^{1}$ \\ ${ }^{1}$ Institute for Research in Molecular Medicine, Kubang Kerian, Kelantan. \\ ${ }^{2}$ School of Medical Sciences, Universiti Sains Malaysia, Kubang Kerian, Kelantan. \\ ${ }^{3}$ Hospital Raja Perempuan Zainab II, 15586 Kota Bharu, Kelantan, Malaysia
}

Submitted: August 19, 2013; Approved: April 17, 2014.

\begin{abstract}
An in-house loop-mediated isothermal amplification (LAMP) reaction was established and evaluated for sensitivity and specificity in detecting the presence of Salmonella Typhi (S. Typhi) isolates from Kelantan, Malaysia. Three sets of primers consisting of two outer and 4 inner were designed based on locus STBHUCCB_38510 of chaperone PapD of $S$. Typhi genes. The reaction was optimised using genomic DNA of $S$. Typhi ATCC7251 as the template. The products were visualised directly by colour changes of the reaction. Positive results were indicated by green fluorescence and negative by orange colour. The test was further evaluated for specificity, sensitivity and application on field samples. The results were compared with those obtained by gold standard culture method and Polymerase Chain Reaction (PCR). This method was highly specific and -10 times more sensitive in detecting $S$. Typhi compared to the optimised conventional polymerase chain reaction (PCR) method.
\end{abstract}

Key words: loop-mediated isothermal amplification (LAMP), Salmonella Typhi.

\section{Introduction}

Salmonella enterica subspecies enterica serovar Typhi ( $S$. Typhi) causes typhoid fever, a systemic febrile illness in humans. It is transmitted by the fecal-oral route, mainly via contaminated food and water. This disease remains an important cause of global morbidity and mortality, especially in developing countries, with an estimated annual incidence of 21 million cases and more than 700,000 deaths reported worldwide (Wain et al., 2003). In Malaysia, $S$. Typhi is endemic with 1-4 cases per 100,000 populations (http://www.dph.gov.my/cdc/Disease List.htm).

A rapid and sensitive method for the detection of $S$. Typhi would help both in preventing the spread of outbreaks and in clinical diagnosis. The conventional methods for the detection of Salmonella require multiple subculture steps, followed by biochemical and serological confirmation, taking more than 3 days to get the result (ISO, 2003). Molecular methods such as PCR, real-time PCR, and DNA microarray, have been successfully used to detect a number of food-borne bacterial pathogens (Li et al., 2009; Malorny et al., 2008; Wattiau et al., 2008; Zhu et al., 1996). However these methods require a well-trained staff and sophisticated equipment which generally are not available in developing countries or point-of-care testing facilities (Curtis et al., 2008). Therefore, a simple, rapid, sensitive and specific test to diagnose $S$. Typhi infections is needed to screen patient samples, especially in developing countries where resources are limited.

Loop-mediated isothermal amplification (LAMP) has been reported to amplify DNA with high sensitivity, specificity and rapidity for the detection of pathogens; $M y$ cobacterium avium subsp. Paratuberculosis (Enosawa et al., 2003), Salmonella species (Hara-Kudo et al., 2005), Yersinia pseudotuberculosis (Horisaka et al., 2004), Human immunodeficiency virus type 1(Hosaka et al., 2009), fish nocardiosis (Itano et al., 2006), Salmonella species (Li et al., 2009), Salmonella enterica isolates (Ohtsuka et al., 
2005), dengue virus serotypes (Parida et al., 2005) and Salmonella Serovars (Ueda and Kuwabara, 2009) ' LAMP requires a set of three specially designed primers termed as inner (LF, LB, FIP and BIP) and outer (F3 and B3) that recognize a total of eight distinct sequences on the target DNA. The FIP and BIP primers consist of sequences of sense (F2 and B2) and antisense (F1c and B1c) strands of the target DNA to initiate the LAMP reaction (Notomi et al., 2000). It uses single amplification period and temperature at 60 to $65^{\circ} \mathrm{C}$ for $1 \mathrm{~h}$. The product can be visualised directly by turbidity due to the accumulation of a by-product of the amplification, magnesium-pyrophosphate. Direct visual identification can be further enhanced by the addition of an intercalating fluorescent dye such as Pico or SYBR Green, where the amplification by-product, pyrophosphate binds and removes the manganese ion from the calcein to irradiate the fluorescence. Positive LAMP products also exhibit a ladder-like pattern of bands when observed by gel electrophoresis (Mori et al., 2001). Thus, in this study, an in-house LAMP method was developed for a rapid, sensitive and specific detection of $S$. Typhi using primers that were designed based on a published STBHUCCB_38510 locus of $S$. Typhi gene (Figure 1 and Table 1). Its specificity and sensitivity for the detection of $S$. Typhi was assessed and further evaluated on clinical samples suspected of $S$. Typhi.
The results were compared with gold standard culture methods and PCR assays.

\section{Materials and Methods}

\section{Bacterial strains and DNA extraction}

A total of 87 bacteria strains consisting of $30 \mathrm{~S}$. Typhi, 38 other Salmonella serovars and 19 non-Salmonella species were used in this study. They were obtained from the Institute of Research in Molecular Medicine (INFORMM), Universiti Sains Malaysia's Culturebank, Kelantan Public Health laboratory and Institute Medical Research (IMR), Malaysia (Table 2). A S. Typhi ATCC7251 strain was used as a positive control and for sensitivity testing of LAMP. The bacteria were identified previously using a procedure based on the EN 1284:1997 method of the European Committee for Standardisation and the Bacteriological Analytical Manual Method of the Food and Drug Administration, USA. Genomic DNA was extracted from the enrichment culture broth by boiling method as previously described by Aziah et al., 2007).

\section{Design of LAMP primers}

Species-specific primers were designed manually based on a published hypothetical STBHUCCB_38510 gene of P-stx-12 (GenBank accession no. CP_003278), CT

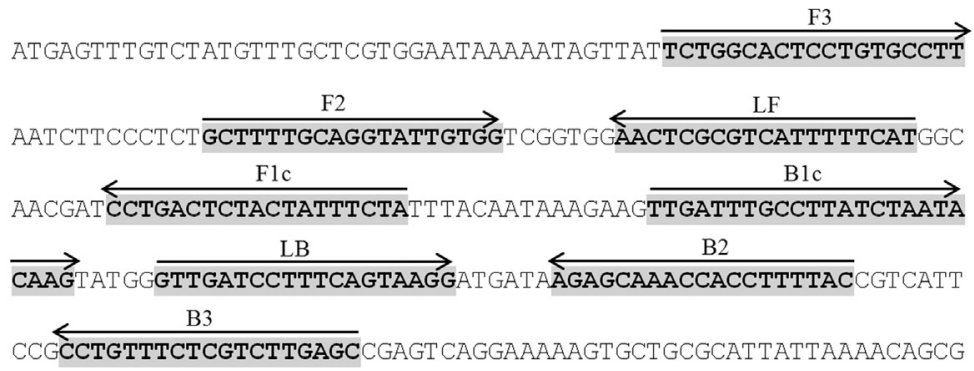

Figure 1 -STBHUCCB_38510 gene sequence and location of designed primers (highlighted in bold). Arrows indicate the position and direction of the primers. FIP primer consists of F1c and F2, while BIP consists of B1c and B2.

Table 1 - PCR and LAMP primers used in this study.

\begin{tabular}{|c|c|c|}
\hline Primer & Sequence of the primer & Position of the primer at STBHUCCB_38510 gene \\
\hline \multirow[t]{2}{*}{ SalTy38510 FIP (F1cF2) } & $5^{\prime}$ tagaaatagtagagtcagg ttttt gcttttgcaggtattgtgg $3^{\prime}$ & $127-145$ \\
\hline & & $73-92$ \\
\hline \multirow[t]{2}{*}{ SalTy38510 BIP (B1cB2) } & $5^{\prime}$ ttgccttatctaatacaag ttttt gtaaaaggtggtttgctct $3^{\prime}$ & $161-184$ \\
\hline & & $215-233$ \\
\hline SalTy38510 F3 & $5^{\prime}$ tctggcactcctgtgcett 3 , & $41-60$ \\
\hline SalTy38510 B3 & $5^{\prime}$ gctcaagacgagaaacagg $3^{\prime}$ & $244-262$ \\
\hline SalTy38510 LF & $5^{\prime}$ atgaaaaatgacgcgagtt 3 ' & $99-117$ \\
\hline SalTy38510 LB & $5^{\prime}$ gttgatcctttcagtaagg 3', & $190-208$ \\
\hline
\end{tabular}


Table 2 - Bacterial strains used in this study.

\begin{tabular}{|c|c|}
\hline & Bacteria strains \\
\hline$S$. Typhi strains & S. Typhi ATCC7251 (Positive control), 30local $S$. Typhi isolates \\
\hline Other Salmonella serovars & $\begin{array}{l}\text { 1.S. Typhimurium ATCC14028, 2.S. Typhimurium MOB 778/05, 3.S.Choleraesuis ATCC7001, 4.S. Paratyphi } \\
\text { B MK160/05, 5.S. Paratyphi B MR729/04, 6.S.Paratyphi C MOB2592/05, 7.S.Braenderup } \\
\text { MOB316/06, 8.S. Walter MOB269/06, 9. S. Paratyphi A, 10.S. Uppsala D1354/07, 11.S. Farsta } \\
\text { D1361K/07, 12.S. BrooklynD1726K07, 13.S. Richmond D1832K/07, 14.S. Bordes D1874K/07, 15.S. Bordeaux } \\
\text { D2213K/07, 16.S. Ayton D2599K/07, 17.S. Virchow D267K/07, 18.S. Rissen D3125K/07, 19.S. Idikan } \\
\text { MOB265/05, 20.S. Abony D3886K/07, 21.S. Limete D3872K/07, 22.S. Albert MK516/06, 23. S. Eppendorf } \\
\text { MOB120/05, 24.S. Corvallis MOB1254/06, 25.S. Hato MOB3233/05, 26.S.Poona ATCC04840, 27.S.Heidel- } \\
\text { berg 3293/07, 28.S. Kibi ATCC7001, 29.S.Emek MK160/05, 30.S. Kissi MR729/04, 31.S. Djakarta } \\
\text { MOB2592/05, 32.S. Vegasack MOB316/06, 33.S. Assimie MOB269/06, 34.S. DraganaB15527/05, 35.S. } \\
\text { Lavochelle D1354/07, 36.S. Tshiogure D1361K/07, 37.S. Tshiogure D1726K07, 38.S. Oramien D1832K/07 }\end{array}$ \\
\hline Non Salmonella species & $\begin{array}{l}\text { 1.Escherichia coli (E.coli) E91EHEC, 2.E.coli B2426, 3.E. coli B1776, 4.E. coli 03-5446, 5.E. coli 0156C, 6.E. } \\
\text { coli 0157C, 7.E.coli E89, 8.Shigella flexneri (Sh.flexneri) S307/IMR, 9.Sh. flexneri SF480, 10.Sh. Boydii } \\
\text { S631/IMR, 11.Sh.sonnei S37/IMR, 12.Sh. dysentery S375/IMR, 13.Acinetobacter baumannii Malaysian iso- } \\
\text { late, 14.Klebsiella pneumoniae (K. pneumoniae) SP1203/03, 15.Pseudomonas aeruginosa Malaysian iso- } \\
\text { late, 16.Vibrio cholerae (V. cholera) J2119, 17.V. cholerae J2127, 18.K. pneumoniae U8580, 19.E.coli E104 } \\
\text { EHEC }\end{array}$ \\
\hline
\end{tabular}

S: Salmonella; E: Escherichia; Sh: Shigella; V: Vibrio; K: Klebsiella.

18 (GenBank accession no.AL_627280) and Ty2 (GenBank accession no AE_014613) of S. Typhi. Three sets of primers were designed: F3 and B3; FIP (F1cF2) and BIP (B1cB2); and LF and LB (Figure 1 and Table 2). The specificity of the designed primers was confirmed using Blast program on the National Center for Biotechnology server (http:/www.ncbi.nlm.nih.gov).

\section{LAMP assay}

LAMP reactions were previously optimized their Betaine and dNTP concentrations, amplification temperatures and incubation periods (unpublished data). The optimised LAMP reaction was carried out in a $25 \mu \mathrm{L}$ reaction mixture containing $12.5 \mu \mathrm{L}$ of $2 \mathrm{x}$ Thermopol buffer (New England Biolabs, UK), $8 \mathrm{mM} \mathrm{MgSO}_{4}, 0.8 \mathrm{M}$ betaine (Sigma-Aldrich, St. Louis, MO), $2 \mathrm{mM}$ of each deoxynucleoside triphosphate (dNTP)(Promega, USA), $40 \mathrm{pMol}$ of FIP and BIP primers, 5 pMol of F3 and B3 primers, $20 \mathrm{pMol}$ of LF and LB primers, $8 \mathrm{U}$ of $B s t$ DNA polymerase, $2 \mu \mathrm{L}$ of DNA template, $0.02 \mu \mathrm{L}$ of Calcein (Merck, Germany); and the mixture was brought to $25 \mu \mathrm{L}$ volume with distilled water. The reaction was incubated at $63{ }^{\circ} \mathrm{C}$ for $60 \mathrm{~min}$ and terminated by heating at $80{ }^{\circ} \mathrm{C}$ for 2 min using heating block. The product was visualised directly with fluorescent green indicating a positive reaction and an orange colour indicating a negative reaction. The images of the reaction tubes were captured using a camera (Panasonic DMC-FHI). Genomic DNA of Salmonella Typhi ATCC7251 was used as a positive control and in the optimisation process.

\section{Specificity of the LAMP assay}

To assess the specificity of the assay, LAMP reaction was carried out on the DNA of confirmed positive cultures of 30 S. Typhi, 38 other Salmonella serovars and 19 non- Sal- monella species (Table 1). S. Typhi ATCC7251 strain was used as a positive control and the DNA extracted from negative cultures of $S$. Typhi was used as a negative control. Each DNA was tested by LAMP at least twice.

\section{Sensitivity of the LAMP assay}

The sensitivity of the assay was determined using 10 -fold serial dilutions of an overnight culture of $S$. Typhi ATCC7251 strain in nutrient broth. To count the bacteria, $100 \mu \mathrm{L}$ aliquot of appropriate dilutions were spread in duplicate on nutrient agar plates and colonies on these plates were counted after incubation for $24 \mathrm{~h}$ at $37^{\circ} \mathrm{C}$. A $100 \mu \mathrm{L}$ aliquot of each dilution $\left(10^{8} \mathrm{cfu} / \mathrm{mL}\right.$ to $\left.10^{4} \mathrm{cfu} / \mathrm{mL}\right)$ was used to extract the DNA by boiling method (Aziah et al., 2007). Two $\mu l$ of the extracted DNA was added to the LAMP reaction. The results were compared with the sensitivity result obtained by conventional PCR.

PCR was conducted and optimised in a $50 \mu \mathrm{L}$ reaction mixture containing $2.5 \mathrm{mM} \mathrm{MgCl}, 0.2 \mathrm{M}$ of each dNTP (Promega, USA), 2.5U of Taq polymerase (Promega, USA), 20 pmol of F3 and B3 primers and $2 \mu \mathrm{L}$ of DNA. PCR was performed at $94^{\circ} \mathrm{C}$ for $5 \mathrm{~min}$, followed by 35 cycles of $94^{\circ} \mathrm{C}$ for $1 \mathrm{~min}, 50{ }^{\circ} \mathrm{C}$ for $1 \mathrm{~min}, 72^{\circ} \mathrm{C}$ for $1 \mathrm{~min}$ and a final extension step at $72{ }^{\circ} \mathrm{C}$ for $10 \mathrm{~min}$. PCR products were separated by electrophoresis on a $2 \%$ agarose gel, stained with ethidium bromide and visualised by UV translumination.

\section{Clinical validation of LAMP for diagnosis}

To assess the ability of LAMP method to detect $S$. Typhi from clinical samples, 60 BACTEC blood culture broths suspected of $S$. Typhi were used in this study. These culture broths were obtained from the Diagnostic Laboratory of Microbiology and Parasitology Department, Universiti Sains Malaysia and Diagnostic Laboratory of Microbiology Department, Hospital Raja Perempuan Zainab II (HPRZ II), 
Kota Bharu, Kelantan Malaysia with the IRB approval. The DNA was also extracted by boiling method(Aziah et al., 2007). The LAMP assay was carried out twice for each sample. To confirm the specificity of DNA band produced by LAMP, $5 \mu \mathrm{L}$ of the products were digested with restriction enzyme Hinfl (New England Biolabs) which was analysed to be specific only to $\mathrm{S}$. Typhi amplified sequence region. The reaction was set according to the manufacture's instruction. The restriction fragments were separated by electrophoresis on a $2 \%$ agarose gel, stained with ethidium bromide and visualised by UV translumination. The results were further confirmed by biochemical culture method. Each DNA of the samples was tested by LAMP at least twice.

\section{Results}

\section{Specificity of the LAMP assay using bacterial strains}

The LAMP reaction only detected DNA from the thirty isolates of $S$. Typhi used in this study but not from the 38 other Salmonella serovars and 19 non Salmonella species (Figure 2A, 2B and 2C).
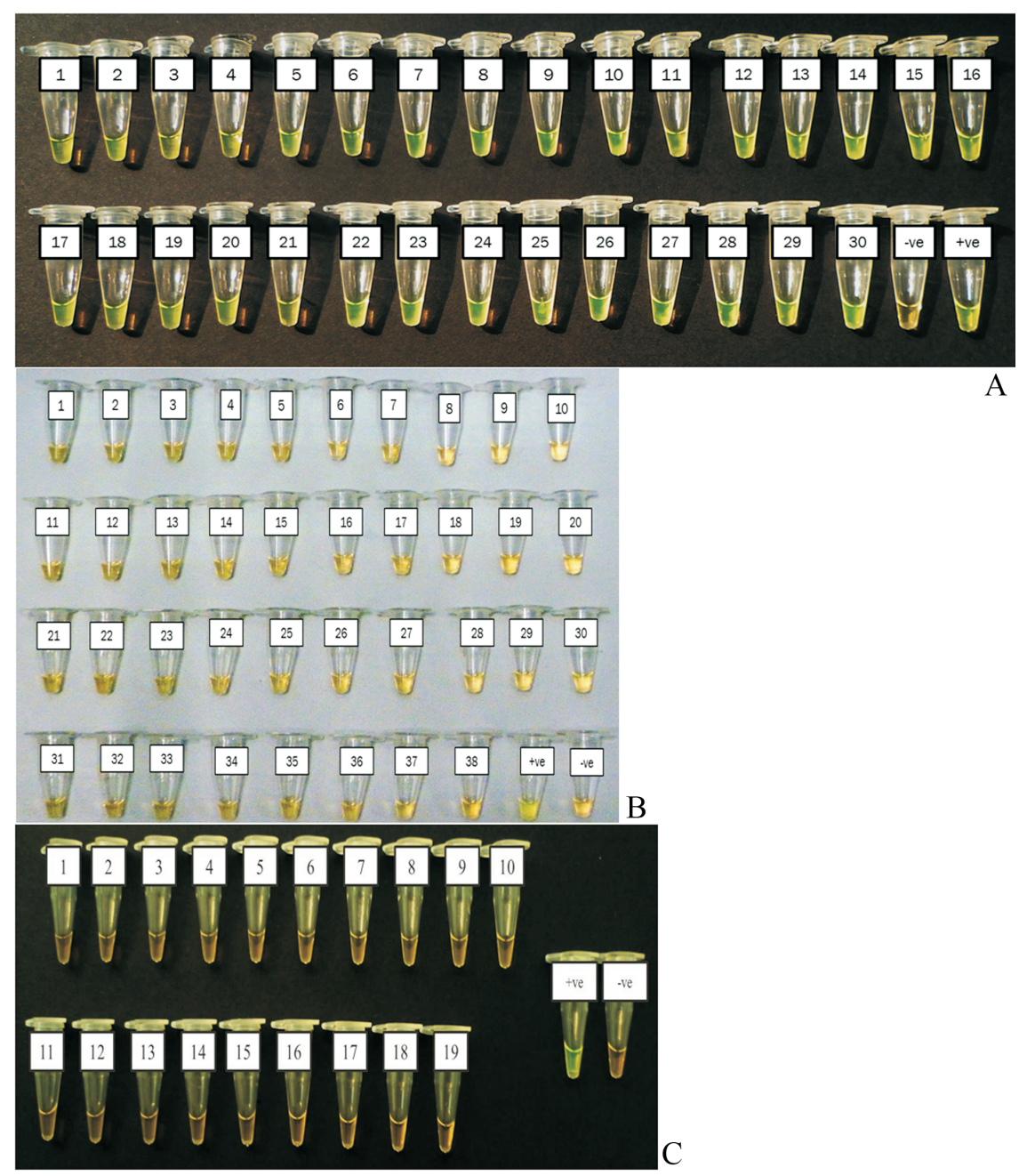

Figure 2 - Specificity of LAMP assay for the detection of Salmonella Typhi genomic DNA by direct visualization. (A) Salmonella Typhi 1-30 isolates. (B) Other Salmonella serovars. 1. Salmonella Typhimurium (S. Typhimurium) ATCC14028, 2.S Typhimurium MOB 778/05, 3.S.Choleraesuis ATCC7001, 4.S.Paratyphi B MK160/05, 5.S. Paratyphi B MR729/04, 6.S.Paratyphi C MOB2592/05, 7.S.Braenderup MOB316/06, 8.S.Walter MOB269/06, 9. S.Paratyphi A, 10.S. Uppsala D1354/07, 11.S. Farsta D1361K/07, 12.S. Brooklyn D1726K07, 13.S. Richmond D1832K/07, 14.S. Bordes D1874K/07, 15.S. Bordeaux D2213K/07, 16.S. Ayton D2599K/07, 17.S. Virchow D267K/07, 18.S. Rissen D3125K/07, 19.S. IdikanMOB265/05, 20.S. Abony D3886K/07, 21. S. Limete D3872K/07, 22.S. Albert MK516/06, 23. S. Eppendorf MOB120/05, 24.S. Corvallis MOB1254/06, 25.S. Hato MOB3233/05, 26.S.Poona ATCC04840, 27.S. Heidelberg 3293/07, 28.S. Kibi ATCC7001, 29.S.Emek MK160/05, 30.S. Kissi MR729/04, 31.S. Djakarta MOB2592/05, 32.S. Vegasack MOB316/06, 33.S. Assimie MOB269/06, 34.S. DraganaB15527/05, 35.S. Lavochelle D1354/07, 36.S. Tshiogure D1361K/07, 37.S. Tshiogure D1726K07, 38. S. Oramien D1832K/07. (C) Non Salmonella species. 1.Escherichia coli (E. coli) E91EHEC, 2.E.coli B2426, 3.E. coli B1776, 4.E. coli 03-5446, 5.E. coli 0156C, 6.E. coli 0157C,7.E.coli E89, 8.Shigella flexneri (Sh. flexneri) S307/IMR, 9.Sh. flexneri SF480, 10.Sh. boydii S631/IMR, 11.Sh.sonnei S37/IMR, 12.Sh. dysentery S375/IMR, 13.Acinetobacter baumannii Malaysian isolate, 14.Klebsiella pneumoniae (K. pneumoniae) SP1203/03,15.Pseudomonas aeruginosa Malaysian isolate, 16.Vibrio cholerae (V. cholera) J2119,17.V. cholerae J2127, 18.K. pneumoniae U8580, 19.E.coli E104 EHEC, -ve: negative control and +ve: positive control(Salmonella Typhi ATCC7251 strain). 


\section{Sensitivity of the LAMP assay}

The sensitivity of the LAMP assay used in this study was $20 \mathrm{CFU} /$ reaction while for the optimised PCR assay was 200 CFU (Figure 3A, 3B and 3C). Thus, the sensitivity of the LAMP assay used in this study was 10 times higher than that of the optimised conventional PCR.

\section{Evaluation on clinical samples}

Evaluation of the LAMP assay on 60 clinical samples showed $100 \%$ agreement with gold standard culture methods and PCR assays, where four tubes (Tubes 1-4) of the confirmed positive cultures of $S$. Typhi were also positive by LAMP method while the other 56 negative cultures were also negative by LAMP (Figure 4A). Same results were also obtained by PCR assay (Figure 4B). These positive LAMP products were successfully digested with HinfI enzyme that was specific only to the amplified STBHUCCB_38510 gene of the $S$. Typhi (Figure 5).

\section{Discussion}

Simple, specific and sensitive diagnostic tests are needed for early detection of pathogens, especially in low resource-settings. Current diagnosis of $S$. Typhi is via culturing techniques and molecular methods such as PCR and real-time PCR (Levy et al., 2008; Malorny et al., 2008). However, the conventional culture method is time- consuming and can take more than 3 days to obtain results (Hara-Kudo et al., 2005). Despite the rapidity and sensitivity provided by PCR-based detection methods, they are not widely used in private clinics or health care settings due to

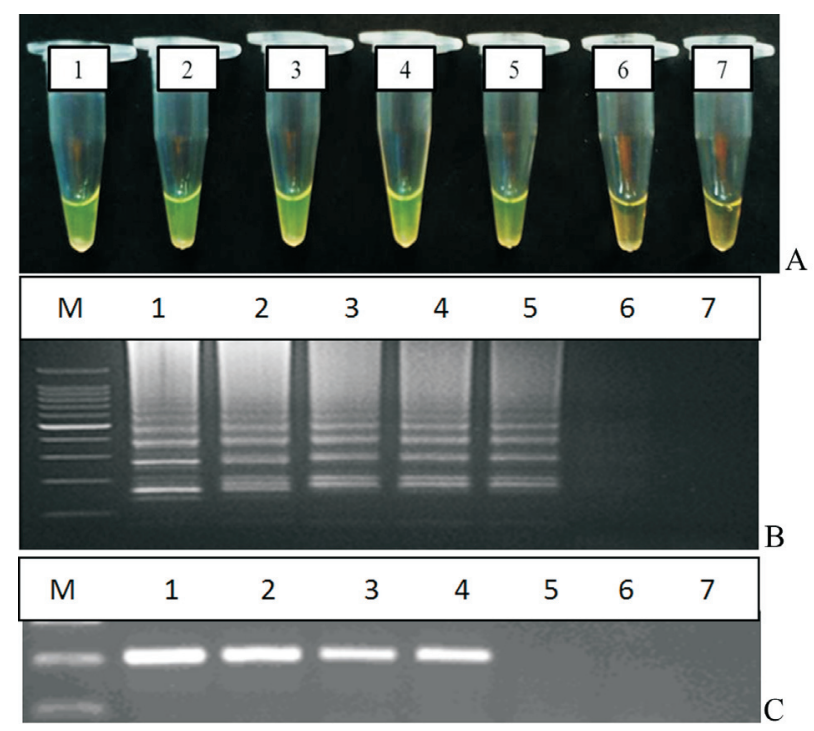

Figure 3 - Sensitivity of $(3 A \& 3 B)$ LAMP observed by direct visualisation and agarose gel electrophoresis respectively and (3C) PCR assay. M: DNA marker,Tube/lane 1:2 × $10^{5} \mathrm{cfu}$, tube/lane $2: 2 \times 10^{4} \mathrm{cfu}$, tube/lane 3 : $2 \times 10^{3} \mathrm{cfu}$, tube/lane $4: 2 \times 10^{2} \mathrm{cfu}$, tube/lane $5: 2 \times 10^{1} \mathrm{cfu}$, lane $6: 2 \times 10^{0}$ cfu, lane 7:-ve control.
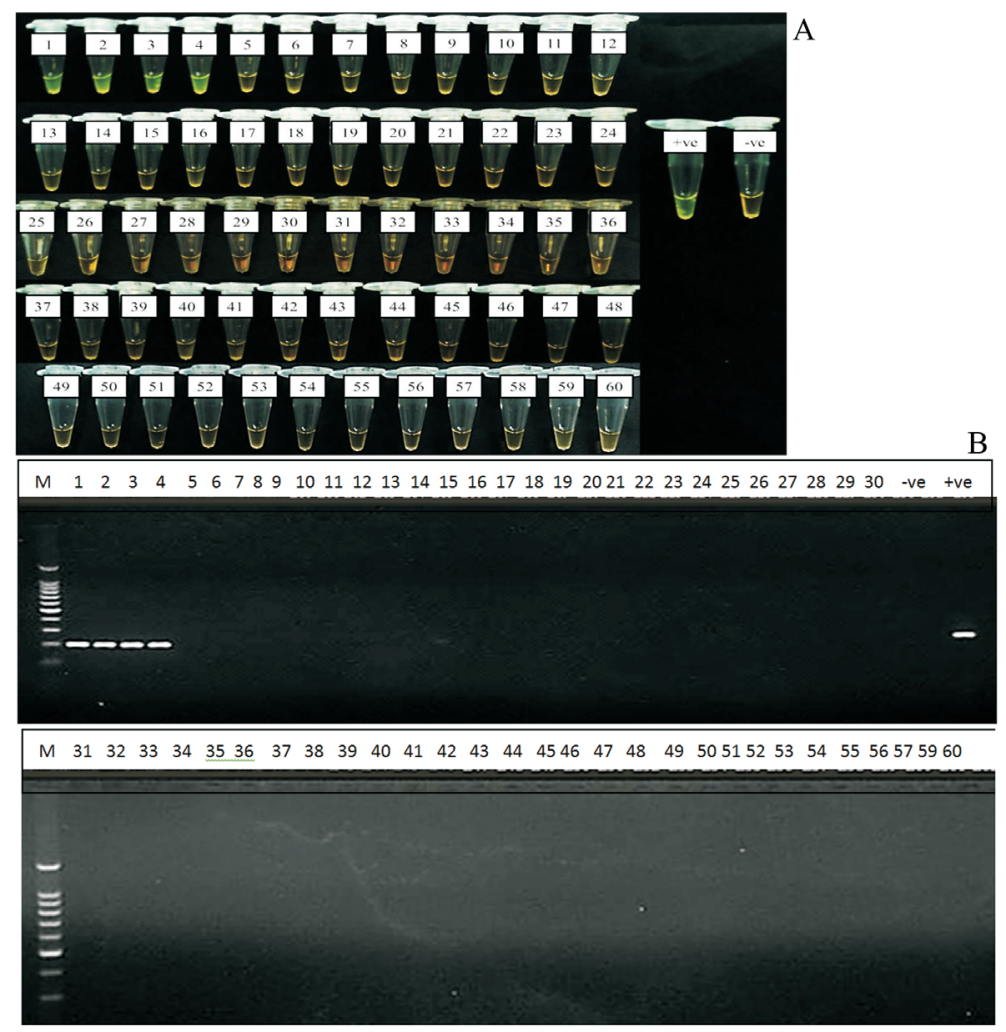

Figure 4 - Evaluation of LAMP assay on 60 clinical samples. Sample 1 to 4 were positive with both LAMP $(A)$ and PCR $(B)$ assays;-ve: negative control and +ve: positive control (Salmonella Typhi ATCC7251 strain). 


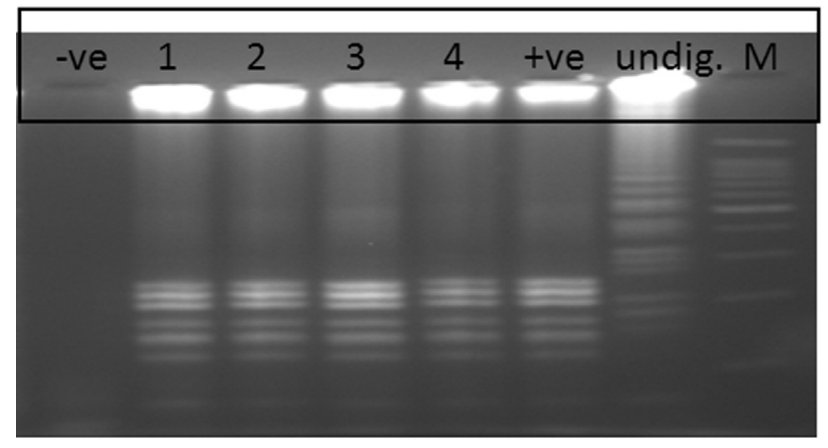

Figure 5 - Digestion of LAMP product with Hinfl restriction enzyme.-ve:Negative LAMP product; lane 1-4: Positive LAMP samples cut with HinfI enzyme; +ve: Positive control LAMP product cut with HinfI enzyme; Undig: Undigested LAMP product of positive control and M: 100 bp marker.

the need of sophisticated equipment and well-trained staff to conduct the testing.

In this study, we have successfully established and optimised an in-house LAMP method based on a hypothetical gene locus STBHUCCB_38510 of $S$. Typhi strains P-stx-12, CT18 and Ty2. The LAMP reactions were optimised at $63{ }^{\circ} \mathrm{C}$ for $1 \mathrm{~h}$ with $0.8 \mathrm{M}$ betaine, $2.0 \mathrm{mM}$ dNTP and $8 \mathrm{mM} \mathrm{MgSO}_{4}$ concentration. This particular-LAMP reaction detected only $\mathrm{S}$. Typhi isolates and not the other Salmonella and non-Salmonella strains tested in this study. The method was also able to differentiate between $S$. Typhi and its closely related bacteria species (e.g., $S$. Typhimurium and $S$. Paratyphi A). Therefore this LAMP could be used to detect and differentiate $S$. Typhi from other Salmonella and non-Salmonella species.

For the analytical sensitivity, our study showed that this in-house LAMP assay is 10 times more sensitive than PCR assay, which is in agreement with results of a previous study (Etano et al., 2006). Therefore it could be a better alternative method for screening samples with small amount of $S$. Typhi that might escape the PCR detection.

Evaluation of this in-house LAMP assay on 60 BACTEC blood culture broths further supported its promising potential to be used in the diagnosis of typhoid fever as the assay correctly identified four samples as positive with no false positive or false negative results (100\% specificity and sensitivity) as compared to the biochemical tests and PCR assay. The specificity of the LAMP product was further confirmed by digestion with Hinfl restriction enzyme where the enzyme has recognised only the $S$. Typhi amplified sequence.

Due to the simplicity, specificity and cost advantages offered by this in-house LAMP, it could potentially be used at resource-limited settings especially in the developed and under developed countries. However, this LAMP cannot be used at point-of-care (POC) because it is still requires electricity for BACTEC blood culture incubation, DNA preparation and incubation of the reaction. Therefore, our on-going research is looking for the DNA extraction method without the need of electricity and innovating the portable heating block that can be operated using battery or solar for incubation of the reaction.

In conclusion, in-house LAMP assay established in this study is a rapid, sensitive and specific method that could potentially be used for the detection of $S$. Typhi at low-resource settings. However this LAMP method is only recommended for screening purposes and needs to be further confirmed with gold standard methods which are culture method and PCR.

\section{Acknowledgments}

The authors would like to thank Ms Haslizai Hassan for her technical assistance. This study was supported by the 'Isothermal amplification' research project funded by the Ministry of Higher Education (MoHE), Malaysia and USM Research University Cluster Grant 1001/PSKBP/8630017.

\section{Conflict of Interest}

All authors declare to have no conflict of interest.

\section{References}

Aziah I, Ravichandran M, Asma I (2007). Amplification of ST50 gene using dry-reagent-based polymerase chain reaction for the detection of Salmonella Typhi. Diag Microb and Infec Dis 59:373-377.

Communicable Disease Control Section, Communicable Disease Control Section, Disease Control Division, Ministry of Health Malaysia. 2008. Typhoid (Typhoid fever).

Available at http://www.dph.gov.my/cdc/Disease List.htm. Acessed 11 Nov 2009.

Curtis KA, Rudolph DL, Owen SM (2008). Rapid detection of HIV-1 by reverse transcription, loop-mediated isothermal amplification (RT-LAMP). J Virol Methods 151:264-270.

Enosawa M, Kageyama S, Sawai K (2003). Use of loop-mediated isothermal amplification of the IS900 sequence for rapid detection of cultured Mycobacterium avium subsp. Paratuberculosis. J Clin Microbiol 41(9):4359-4365.

Hara-Kudo Y, Yoshino M, Kojima T (2005). Loop-mediated isothermal amplification for the rapid detection of Salmonella. FEMS Microbiol. Lett 253:155-161.

Horisaka T, Fujita K, Iwata T (2004). Sensitive and specific detection of Yersinia pseudotuberculosis by loop-mediated isothermal amplification. J Clin Microbiol 42:5349-5352.

Hosaka N, Ndembi N, Ishizaki A (2009). Rapid detection of human immunodeficiency virus type 1 group $\mathrm{M}$ by a reverse transcription-loop-mediated isothermal amplification assay. J Virol Methods 157:195-199.

ISO (6579:2003). Microbiology of food and animal feeding stuffs. Horizontal method for the detection of Salmonella International Organization for Standardization, Geneva, Switzerland.

Itano T, Kawakami H, Kono $\mathrm{T}$ (2006). Detection of fish nocardiosis by loop-mediated isothermal amplification. J Appl Microbiol 100:1381-1387. 
Levy H, Diallo S, Tennant SM (2008). PCR method to identify Salmonella enteric serovars Typhi, Paratyphi A, and Paratyphi B among Salmonella isolates from the blood of patients with clinical enteric fever. J Clin Microbiol 46:1861-1866.

Li X, Zhang S, Zhang H (2009). A loop-mediated isothermal amplification method targets the phoP gene for the detection of Salmonella in food samples. Int J Food Microbiol 133:252-258.

Malorny B, Lofstrom C, Wagner M (2008). Enumeration of Salmonella bacteria in food and feed samples by real-time PCR for quantitative microbial risk assessment. Appl Environ Microbiol 74:1299-1304.

Mori Y, Nagamine K, Tomita N (2001). Detection of loop-mediated isothermal amplification reaction by turbidity derived from magnesium pyrophosphate formation. Biochem Biophys Res Commun 289(1):150-154.

Notomi T, Okayama H, Masubuchi H (2000). Loop-mediated isothermal amplification of DNA. Nucleic Acids Res 28 (12): e63.

Ohtsuka K, Yanagawa K, Takatori K, Hara-Kudo Y (2005). Detection of Salmonella enterica in Naturally Contaminated Liquid Eggs by Loop-Mediated Isothermal Amplification, and Characterization of Salmonella Isolates. Appl Environ Microbiol. 71(11):6730-6735.

Parida M, Horioke K, Ishida H (2005). Rapid detection and differentiation of dengue virus serotypes by a real-time reverse transcription-loop-mediated isothermal amplification assay. J Clin Microbiol 43:2895-2903.

Ueda S and KuwabaraY(2009). The rapid detection of Salmonella from food samples by loop-mediated isothermal amplification (LAMP). Biocontrol Sci 14(2):73-76.

Wain J, Diem Nga LT, Kidgell C (2003). Molecular analysis of incHI1 antimicrobial resistance plasmids from Salmonella serovar Typhi strains associated with typhoid fever. Antimicrob Agents Chemother 47:2732-2739.

Wattiau P, Weijers T, Andreoli P (2008). Evaluation of the Premix Test Salmonella, a commercial low-density DNA microarray system intended for routine identification and typing of Salmonella enterica. Int J Food Microbiol 123:293-298.

Zhu Q, Lim CK, Chan YN (1996). Detection of Salmonella Typhi by polymerase chain reaction. J Appl Microbiol 80:244-251.

All the content of the journal, except where otherwise noted, is licensed under a Creative Commons License CC BY-NC. 